(C) 1984. The Genetical Society of Great Britain

\title{
REGULATORY GENE EVOLUTION: ADAPTIVE DIFFERENCES IN EXPRESSION OF ALCOHOL DEHYDROGENASE IN DROSOPHILA MELANOGASTER AND DROSOPHILA SIMULANS
}

\author{
W. J. DICKINSON, ROBERT G. ROWAN AND MARK D. BRENNAN \\ Department of Biology, University of Utah, Salt Lake City, UT 84112 USA
}

Received 9.ix.83

\section{SUMMARY}

In Drosophila melanogaster $\times D$. simulans hybrids, the alcohol dehydrogenase (ADH) electromorphs characteristic of the two parents display tissue- and stage-specific differences in relative level of expression. This implies distinct $c i s$-acting regulatory elements associated with the respective $A d h$ alleles. These cis-acting elements account in part, but not completely, for markedly different overall patterns of ADH expression in the two species. The regulatory patterns seem to be adaptively significant since they correlate with species-specific patterns of ethanol tolerance. The activity differences are accounted for by different levels of enzyme protein, but the underlying mechanisms have not been fully analysed and may be complex. Independent evolution of various aspects of the ADH developmental programme may relate to use of different promoters for transcription of the $A d h$ locus in different developmental contexts. This system illustrates the potential importance of regulatory genes in evolution and provides a model for investigating the molecular basis of evolved regulatory differences.

\section{INTRODUCTION}

Divergent patterns of regulation of homologous genes in related species are of interest in both evolutionary and mechanistic contexts. It has been proposed that changes in gene regulation are important in adaptive evolution, perhaps more so than changes in protein structure (King and Wilson, 1975; Valentine and Campbell, 1975; Wilson, 1976; Hedrick and McDonald, 1980; MacIntyre, 1982). However, the evidence advanced in support of this view is largely indirect. For example, King and Wilson (1975) argued that rates of change in structural loci are poorly correlated with rates of change of gross phenotype, and that the latter changes must therefore be due to other sorts of genetic alteration, possibly affecting gene regulation. On the other hand, several reports provide direct evidence for evolved differences in the developmental regulation of specific proteins but contain no evidence bearing on their adaptive significance (Markert et al., 1975; Dickinson, 1980a; Whitt, 1981).

The extensive information available on the role of alcohol dehydrogenase $(\mathrm{ADH})$ in ethanol utilisation and tolerance in Drosophila provides an opportunity to investigate the regulation of a specific gene relative to a known adaptive function. Studies on $\mathrm{ADH}$ variants in $D$. melanogaster consistently suggest that this enzyme is important in ethanol tolerance (Clarke, 1975; David et al., 1976; David, 1977; McDonald and Ayala, 1978; Ayala and McDonald, 1980; reviewed in Van Delden, 1982). Likewise, differences in total ADH activity among Drosophila species apparently 
relate to differential utilisation of ethanol rich resources (McKenzie and Parsons, 1972; David et al., 1974; McDonald and Avise, 1976). In particular, D. melanogaster, which has a much higher adult level of ADH than its sibling species, $D$. simulans, is much more likely to be found near strongly fermented food resources (e.g., in wineries) and survives exposure to much higher concentrations of ethanol in laboratory experiments.

From a mechanistic point of view, evolved regulatory differences can be useful tools in a genetic and molecular analysis of gene regulation. For example, we have used interspecific Drosophila hybrids to demonstrate complex, cis-acting genetic elements that control the tissue and stage specific expression of linked structural genes. (Dickinson and Carson, 1979; Dickinson, $1980 \mathrm{~b}, 1983$ ). Molecular comparisons of the parental species can provide evidence concerning the level at which these elements operate (Rabinow and Dickinson, 1981) and may lead to identification of relevant DNA sequences. Extensive genetic and molecular studies on ADH in $D$. melanogaster (O'Donnell et al., 1977; Woodruff and Ashburner, 1979a, b; Thatcher, 1980; Benyajati et al., 1980, 1981, 1983) and some comparative work on sequences in D. simulans (M. Bodmer and M. Ashburner, personal communication) provide background information that makes $\mathrm{ADH}$ a favourable system also in this context.

The present study demonstrates that there are important differences in ADH regulation in $D$. melanogaster and $D$. simulans, that these differences are partly under control of cis-acting factors, and that the regulatory patterns correlate with species specific patterns of ethanol tolerance.

\section{Materials AND Methods}

D. melanogaster $y^{59 \mathrm{~b}} \mathrm{z}$, obtained from William K. Baker, and a wild type $D$. simulans stock from Peru, obtained from David R. Wolstenholme, were used for all experiments unless otherwise noted. The $D$. melanogaster stock was chosen because the females hybridise to $D$. simulans more readily than wild type flies. It is fixed for the common $A d h^{\mathrm{F}}$ allele and has total activity and a pattern of expression similar to wild type stocks carrying that allele. Comparative studies employed a variety of additional stocks as noted below. Flies were maintained on standard cornmeal-agar-yeast medium at $25^{\circ} \mathrm{C}$. Unless otherwise noted, larvae were in the late third instar but still actively feeding and adults were females aged seven to ten days.

$\mathrm{ADH}$ in extracts of dissected tissues and whole organisms was analysed following electrophoresis in Agar Noble gels containing $0.1 \mathrm{mg} / \mathrm{ml} \mathrm{NAD}$ as previously described (Dickinson and Carson, 1979), except for the use of $0.54 \mathrm{M}$ ethanol as substrate. Stain intensity was measured with a Quickscan integrating densitometer (Helena Laboratories). Sample concentrations, volumes and staining times were chosen to yield a linear relationship between stain intensity (area under densitometer peak) and enzyme concentration, based on preliminary experiments (correlation coefficient $>0.99$ ).

Cross reacting material (CRM) was measured by radial immunodiffusion. Test plates were prepared in $60 \mathrm{~mm}$ plastic petri dishes and contained $4 \mathrm{ml}$ of 1 per cent agarose in $0.15 \mathrm{M} \mathrm{NaCl}, 0.05 \mathrm{M}$ Tris, $p \mathrm{H} 8.0$ to which $0.05 \mathrm{ml}$ of crude goat anti-ADH serum (a gift of William Sofer) was added just before pouring. Samples ( $15 \mu \mathrm{l}$ of crude extract) were loaded into $3 \mathrm{~mm}$ holes and the gel was left at $4^{\circ} \mathrm{C}$ for two days before staining for $\mathrm{ADH}$ 
activity. The areas of the stained discs were used to determine CRM levels. All samples were analysed on gels along with a series of standards (dilutions of adult $D$. melanogaster extract). The standards were used to determine a line (least squares method, coefficient of correlation $>0.98$ in each case) from which the CRM content of each experimental sample was read as a percentage of that in $D$. melanogaster adults. Control immunotitrations of mixed extracts established that antibody affinity for ADH from the two species is very similar, with the $D$. melanogaster enzyme only slightly preferred.

CRM was measured in samples resolved by electrophoresis using a slight modification of this method. Each band in a lightly stained gel was punched out with a cork borer and dropped into a matching hole in an immunodiffusion plate. These samples were allowed to diffuse and analysed as described above. Calibration was in comparison to a series of standards diluted prior to electrophoresis.

RNA was prepared as described (Rabinow and Dickinson, 1981), except with the addition of $200 \mu \mathrm{g} / \mathrm{ml}$ of proteinase $\mathrm{K}$ (Boehringer) to the extraction buffer. RNA samples were either spotted directly on nitrocellulose or resolved by electrophoresis in agarose gels containing formaldehyde (Lehrach et al., 1977) and transferred to nitrocellulose. In either case, the conditions for binding RNA to nitrocellulose were those given by Thomas (1980) as were the subsequent hybridisation and wash procedures. ADH mRNA was detected by hybridisation to the plasmid sAC-1 (Goldberg, 1980), which contains the complete ADH coding sequence from $D$. melanogaster. Spots or bands visualised by autoradiography were cut out and counted to obtain estimates of relative messenger abundance. Structures near the $5^{\prime}$ ends of larval and adult ADH mRNAs were compared by $S_{1}$ nuclease protection experiments (Berk and Sharp, 1977).

Survival on ethanol was measured by placing 50 individuals per vial at the indicated stages on food prepared from equal volumes of dry instant Drosophila medium (Carolina Biological Supply) and an ethanol:water mixture of the concentration specified.

Where indicated in text or tables, statistical uncertainties represent 95 per cent confidence intervals.

\section{Results}

\section{(i) Regulatory phenotypes}

Cis-acting regulatory variants are readily detected in hybrids, provided products of alleles contributed by the two parents can be resolved by electrophoresis. Differences in cis-acting regulators are revealed as temporal or spatial variation in the ratio of the two products (Dickinson, 1980b, 1983). An analysis of ADH in tissues of $D$. melanogaster $\times D$. simulans hybrids is displayed in fig. 1 . It is clear that the relative expression of the alleles varies among tissues at each stage and that there is a general trend toward preferential expression of the $D$. melanogaster allele in adults. Qualitatively, the pattern differences inferred from these sub-unit ratios in hybrids are confirmed in comparisons of the parental stocks. For example, larvae of the two species have similar total $\mathrm{ADH}$ activities while adults are very different (table 1). However, the differences between species consistently are greater than would be expected from the sub-unit ratios, 
Melanogaster $\times$ simulans hybrids

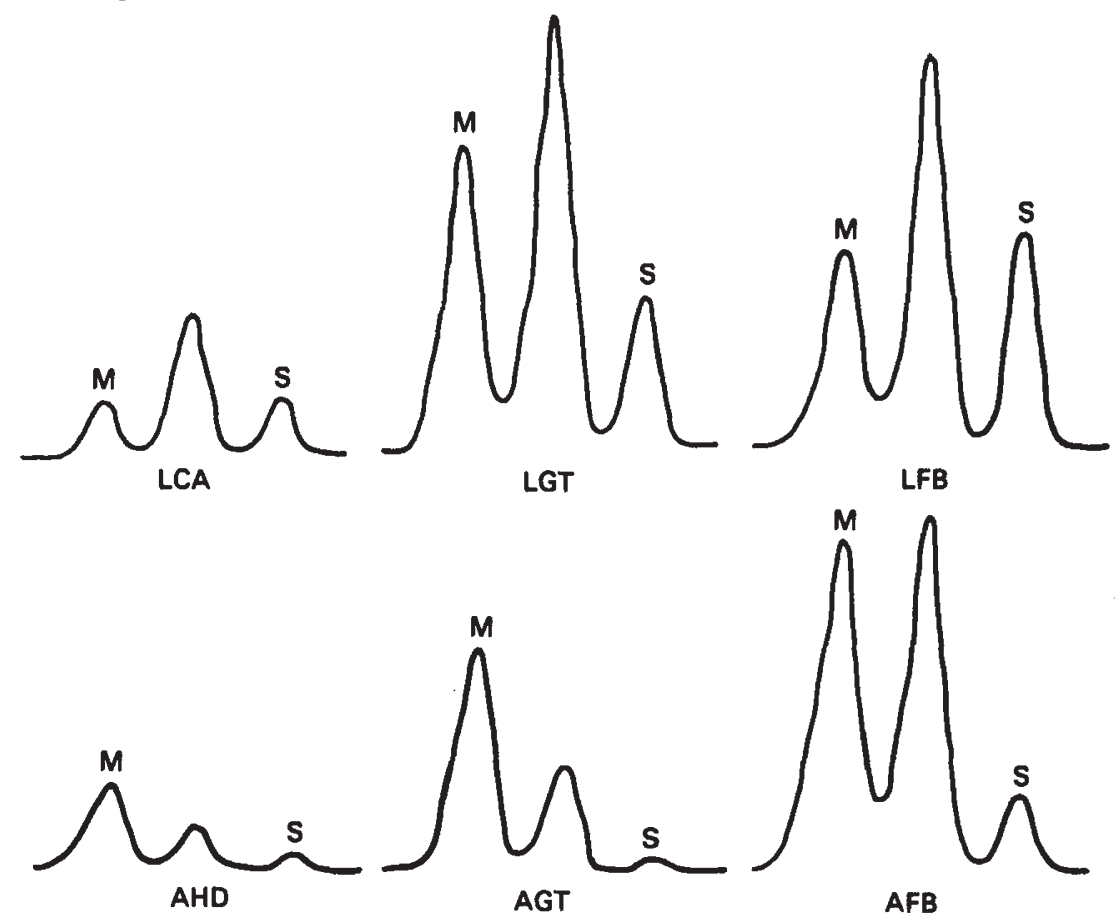

Fig. 1. Tissue and stage specific expression of $D$. melanogaster and $D$. simulans alleles in hybrids. Tissues from five individuals were dissected and pooled. Following homogenisation, an equal volume of each sample was loaded on a gel for electrophoretic analysis. Gels were stained and scanned with a densitometer as described in materials and methods. In each scan, the peak representing the $D$. melanogaster homodimer is to the left and the $D$. simulans homodimer is to the right. The intermediate peak is the heterodimer. Top row, left to right: larval carcass (integument and body wall musculature); larval gut; larval fat body. Bottom row, left to right: adult head; adult gut; adult fat body (with abdominal body wall).

implicating factors in addition to cis-acting regulators. Table 1 summarises data for whole larvae and adults. Similar results are obtained with dissected tissues.

Surprisingly, the total activity in hybrids, particularly adults, is significantly higher than in either parent, possibly because of important differences in physiology. Hybrids have rudimentary ovaries and enlarged fat bodies and their total body weight averages about 25 per cent greater than the parents. ADH activity is much higher in fat body than in ovary and varies dramatically with weight (Clarke et al., 1979). These factors complicate any analysis of trans-acting regulators, but do not affect the demonstration of cis-acting elements, since that depends on the relative expression of two alleles in an individual.

Since a major feature of these regulatory patterns is a shift toward greater relative expression of the $D$. melanogaster allele in adults, we examined the timing of this shift in whole hybrids. The approximately equal expression of alleles characteristic of third instar larvae is also seen in both earlier larval stages as well as in all pupal stages, at least through formation 
TABLE 1

$A D H$ activity in whole larvae and adults of $\mathrm{D}$. melanogaster, D. simulans and hybrids

\begin{tabular}{|c|c|c|}
\hline & Larvae & Adults \\
\hline \multicolumn{3}{|c|}{ Total ADH activity (arbitrary units) ${ }^{1}$} \\
\hline $\begin{array}{l}\text { D. melanogaster } \\
\text { D. simulans } \\
\text { hybrids } \\
\text { average of parents } \\
\text { (compare with hybrids) }\end{array}$ & $\begin{array}{c}206 \pm 19 \\
140 \pm 11 \\
256 \pm 57 \\
173\end{array}$ & $\begin{array}{c}257 \pm 18 \\
61 \pm 4 \\
438 \pm 34 \\
159\end{array}$ \\
\hline \multicolumn{3}{|c|}{ Activity ratio (D. melanogaster/D. simulans) } \\
\hline $\begin{array}{l}\text { Parental stocks } \\
\text { Sub-units in hybrids }{ }^{3}\end{array}$ & $\begin{array}{l}1 \cdot 47 \pm 0 \cdot 17 \\
1 \cdot 16 \pm 0 \cdot 18\end{array}$ & $\begin{array}{l}4.21 \pm 0.08 \\
2 \cdot 17 \pm 0.23\end{array}$ \\
\hline $\begin{array}{l}{ }^{1} \text { All values are determ } \\
\text { in order to be directly com } \\
{ }^{2} \text { Ratios were determi } \\
\text { prepared from equal weigh } \\
{ }^{3} \text { Sub-unit ratios were } \\
\text { for the heterodimer peak t }\end{array}$ & $\begin{array}{l}\text { ain intensity } f \\
\text { ub-unit ratio } \\
\text { ig electroph } \\
\text { luals from th } \\
\text { attributing h } \\
\text { e parental fo }\end{array}$ & $\begin{array}{l}\text { g electrophoresis } \\
\text { ured in hybrids. } \\
\text { of mixed samples } \\
\text { tocks. } \\
\text { activity measured }\end{array}$ \\
\hline
\end{tabular}

of prominent cuticular pigmentation (about one day before eclosion). The sub-unit ratio in newly emerged adults is somewhat variable but, on average, remains close to that seen in larvae. Within two-three days after eclosion, the shift to the preferential expression of the $D$. melanogaster allele is completed. Consistent with these patterns in hybrids, newly emerged adults of the parental stocks have similar total ADH activities while by three days after eclosion the characteristic four fold difference is achieved.

\section{(ii) Comparisons to other strains}

At least with respect to the cis-acting differences, the regulatory patterns found in the standard stocks used in the foregoing experiments are widespread in the respective species. We tested two other wild type $D$. simulans stocks, one from North America and one from Europe, and two laboratory stocks. All yielded essentially identical results both in side by side comparisons and in crosses to the same $D$. melanogaster stock. We also compared ten other $A d h^{F}$ alleles from diverse stocks to that in $y^{59 \mathrm{~b}} z$ in the following design. Each stock (including $y^{590} z$ ) was crossed to a Canton-S wild type stock which is homozygous for $A d h^{\mathbf{s}}$. Larval and adult tissues in the heterozygous progeny were analysed for relative expression of the two alleles as above. The slow allele serves as an internal control against which expression of each independently sampled fast allele is compared. We found no significant difference among the fast alleles examined in this experiment. We similarly tested ten slow alleles against a single fast allele from an Oregon- $R$ wild type stock and found no variability. In all combinations, the fast allele is expressed more strongly in each tissue of both stages. There is some variation in subunit ratio among tissues and stages, with the slow allele tending slightly toward the pattern of expression of the $D$. simulans allele, but the major feature is a systemic difference in level of expression 
rather than tissue- and stage-specific differences. Note that the foregoing only examines equivalence of cis-acting factors in various $A d h^{\mathrm{F}}$ and $A d h^{\mathrm{S}}$ stocks and does not preclude variation in total activity among stocks of either class.

\section{(iii) Adaptive significance}

If $\mathrm{ADH}$ is important in ethanol detoxification, the observed regulatory patterns suggest that differences in ethanol tolerance might be most marked
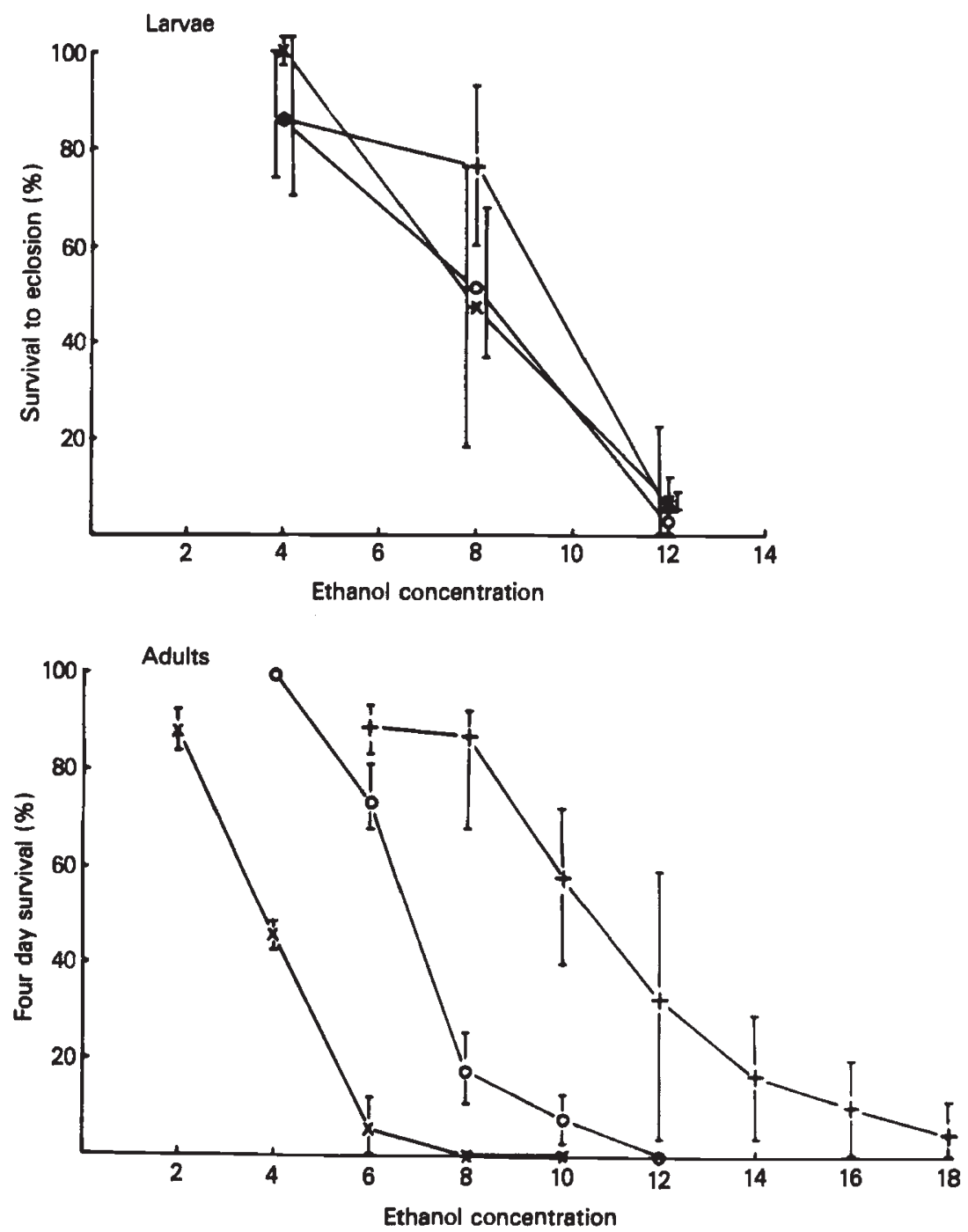

Fig. 2. Survival on ethanol. Early third instar larvae or ten day old adult females were placed on food containing the concentration of ethanol shown. Larvae were scored for survival to eclosion and adults for survival after four days. The points are averages and the vertical lines indicate the range for four replicate experiments. The larval curves are corrected for eclosion percentages of control samples. $x, D$. simulans; $0, D$. melanogaster; + , hybrid. 
in adults. This expectation is confirmed for our stocks by experiments illustrated in fig. 2. Interestingly, adult hybrids are more tolerant than $D$. melanogaster, in accord with their higher levels of $\mathrm{ADH}$.

\section{(iv) Mechanism}

The ADH activity patterns in the two species reflect differences primarily in the amount of enzyme protein present, not differences in catalytic properties, as demonstrated by measurement of cross reacting material (CRM) summarised in table 2. Larvae of each species have a $\mathrm{CRM} /$ activity ratio

TABLE 2

Relationship of CRM to ADH activity ${ }^{1}$

\begin{tabular}{llccc}
\hline \multicolumn{1}{c}{ Species } & Stage & ADH activity & ADH CRM & CRM/Activity \\
\hline D. melangaster & adults & 100 & 100 & 1.0 \\
D. melanogaster & larvae & $78 \cdot 5 \pm 3.5$ & $59.4 \pm 0.76$ & 0.76 \\
D. simulans & adults & $23 \cdot 7 \pm 0.71$ & $29.9 \pm 1.5$ & 1.26 \\
D. simulans & larvae & $52.4 \pm 4.4$ & $57.5 \pm 2.9$ & 1.10 \\
\hline
\end{tabular}

${ }^{1}$ For each series of determinations, $D$. melanogaster adults were used as standards (100 per cent) and all other values are relative. Samples were 1:20 (w:v) mass extracts of ten day old adults or third instar larvae.

somewhat lower than adults, and $D$. simulans has a slightly higher ratio than $D$. melanogaster in each stage. The latter might be due to either greater affinity of the antibody for the $D$. melanogaster enzyme or lower efficiency of the $D$. simulans enzyme. Nevertheless, the major features of the activity patterns are clearly reflected in the CRM measurements. Thus, in $D$. melanogaster both activity and CRM are lower in larvae than in adults, while in $D$. simulans both are about two fold higher in larvae. Likewise, the distribution of activity among the three types of dimers in hybrids reflects primarily the number of molecules of each type. Specifically, the average $D$. melanogaster: $D$. simulans sub-unit ratio estimated from four replicate sets of CRM measurements in hybrids is $1 \cdot 11 \pm 0.15$ for larvae and $2.06 \pm 0.54$ for adults. (Compare with $1 \cdot 16 \pm 0.18$ and $2 \cdot 17 \pm 0.23$, respectively, estimated from activity measurements in table 1.)

We have previously shown that cis-acting genes regulating qualitative differences in tissue specificity of $\mathrm{ADH}$ in species of Hawaiian Drosophila act to control accumulation of ADH mRNA (Rabinow and Dickinson, 1981). The results of messenger measurements related to the subtler differences between $D$. melanogaster and $D$. simulans suggest a more complex situation. Adults of the former species consistently contain more ADH mRNA, but values based on quantitative dot hybridisations indicate a messenger abundance in $D$. melanogaster only $1.31 \pm 0.17$ times that in $D$. simulans. This might represent a minimum estimate since non-specific background would reduce the ratio. Background should be reduced by separating ADH mRNA from other RNA and contaminating DNA by electrophoresis. Indeed, the $A D H$ mRNA abundance ratio measured in this way on the same set of samples is $1 \cdot 71 \pm 0 \cdot 50$. ADH activity was measured in flies from each batch from which RNA was prepared. In all cases, the activity in $D$. melanogaster adults was at least four fold higher 
than in $D$. simulans, consistent with the values reported in table 1 . Thus, the difference in RNA abundance is in the same direction as the enzyme activity (or CRM) difference but is significantly less pronounced.

It has recently been shown that the mRNA produced from the $\mathrm{ADH}$ locus in D. melanogaster is different in larvae and adults (Benyajati et al., 1983). The differences lie in a $5^{\prime}$ leader sequence and may reflect the utilisation of two different promoters and removal of an additional intron from within the untranslated leader of the adult transcript. Sequence homology suggests that $D$. simulans has a similar arrangement $(\mathrm{M}$. Bodmer and $\mathrm{M}$. Ashburner, personal communication). We have compared the fragments protected from $S_{1}$ nuclease digestion when cloned DNA sequences are hybridised to larval or adult ADH mRNA of each species, focusing on a region that encompasses the $5^{\prime}$ end of the larval message and the $3^{\prime}$ splice junction of the adult specific intron in D. melanogaster (Benyajati et al., 1983). The results (plate 1 ) indicate that $D$. simulans also makes distinct ADH messengers with similar stage specificity.

\section{Discussion}

Our central conclusion is that $D$. melanogaster and $D$. simulans regulate ADH differently. This goes beyond a simple quantitative difference in enzyme activity since the differences are stage- and tissue-specific. The differences are partly under control of cis-acting genetic elements. The respective regulatory patterns seem to account for species-specific differences in the temporal pattern of ethanol tolerance. This last conclusion is consistent with earlier reports of McKenzie and Parsons (1972) and McDonald and Avise (1976), although the relationship does not appear to have been recognised previously. We are aware of only a few other instances in which the tissue- or stage-specific regulation of a gene has been related to adaptation. For example, a high level of lysozyme in stomach mucosa appears to be characteristic of ruminants and to be adaptive for their pattern of nutrition (Dobson et al., 1979; White et al., 1982), but the evolutionary distance from the comparison species is much greater than in the present case. Likewise, Allendorf et al. (1983) postulate an adaptive role for a regulatory polymorphism affecting phosphoglucomutase expression in liver of rainbow trout, but the causal connection is less clear than the relationship of $\mathrm{ADH}$ to ethanol tolerance. Wilson et al. (1977) list additional possible cases.

Mechanistically, this system presents several complexities not evident in some of the qualitative regulatory differences we previously analysed in Hawaiian Drosophila. In those cases, cis-acting factors alone were sufficient to account for major regulatory differences (Dickinson and Carson, 1979; Dickinson, $1980 b$ ) and differences in enzyme activity were reflected at the RNA level (Rabinow and Dickinson, 1981 and unpublished). In the present case, the cis-acting component accounts for only about half of the difference seen between species. Differences in RNA abundance seem to account for even less than this. Note that these are unrelated conclusions. It is not surprising that trans-acting factors may contribute to the species difference since such factors have previously been shown to affect ADH level in $D$. melanogaster and to respond to selection for survival on ethanol (McDonald et al., 1977; McDonald and Ayala, 1978; Laurie-Ahlberg et al., 1982). 


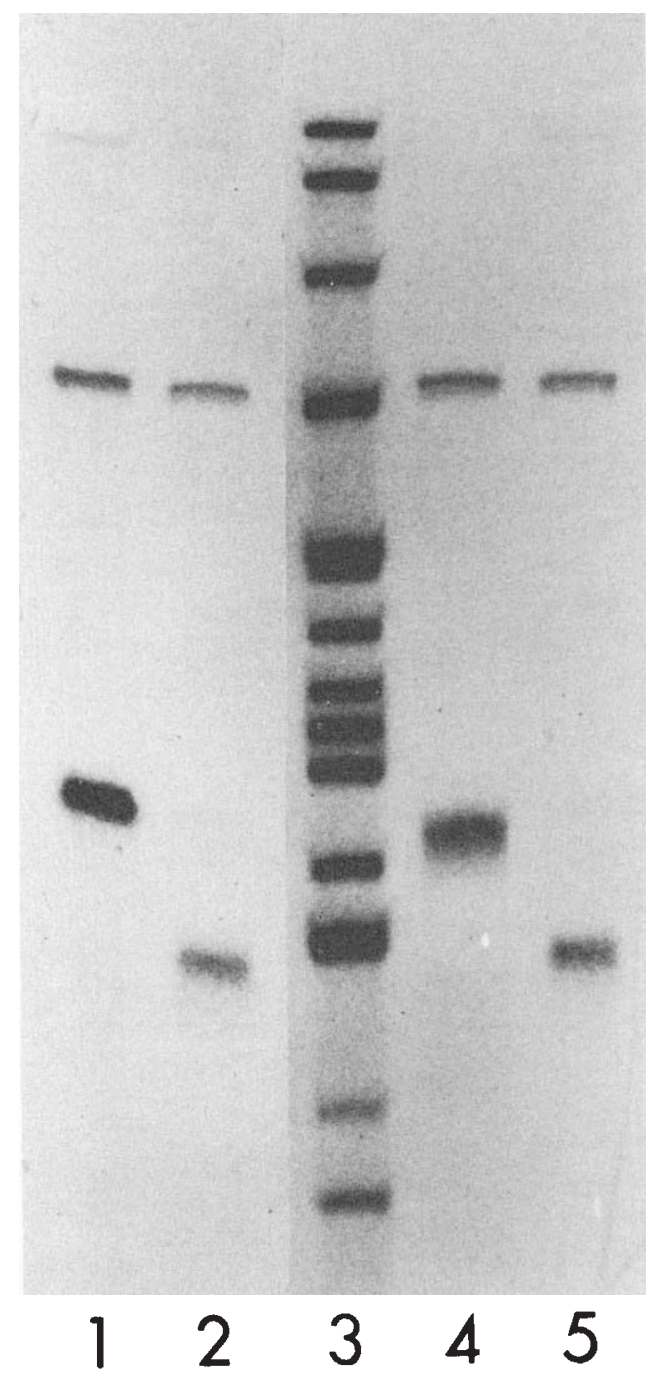

PLATE 1. DNA fragments protected from $\mathrm{S}_{1}$ nuclease digestion by hybridisation to larval and adult ADH mRNA. The DNA is from a subclone extending from the Hind III site beginning at +652 in the numbering system of Benyajati et al., (1983) to a Bam $\mathrm{Hl}$ site 605 base pairs downstream. The results using $D$. melanogaster larval and adult RNAs are shown, respectively, in lanes 1 and 2 and those for $D$. simulans RNAs in lanes 4 and 5 in the same order. The markers in lane 3 are $\mathrm{Hpa}$ II fragments of pBR322. The protection of a smaller $5^{\prime}$ end fragment with adult messenger is expected in the case of $D$. melanogaster since the $3^{\prime}$ splice site for removal of the adult intron falls within a region represented as an intact transcript in the larval messenger (Benyajati et al., 1983). The situation appears to be similar in $D$. simulans. 
Several possibilities remain open concerning the mechanisms underlying these regulatory differences. We would particularly like to note the possibility of an interesting relationship between patterns of regulatory change during evolution and the functional organisation of the $\mathrm{ADH}$ gene. $D$. melanogaster and $D$. simulans express ADH at very similar levels in larvae but very different levels in adults. Thus, it appears that expression in these two stages can evolve more or less independently. We previously have reported a number of similar examples that indicate that various aspects of the developmental program of a specific gene can change independently, all under cis-acting control (Dickinson, 1980b, 1983). We have suggested that these results imply some sort of complexity in the regulatory region of such genes and have published a speculative model involving multiple promoters (Dickinson, 1983). In the present context, we note that the production of distinct ADH mRNA in larvae and adults (Benyajati et al.), provides several opportunities for regulatory elements affecting larval and adult expression to evolve independently. If transcription involves different promoters, as suggested by presence of proximal and distal "TATA" boxes, different sequences may influence the efficiency of utilisation of each. $M$. Bodmer and M. Ashburner (personal communication) have made available a comparison of DNA sequences in and around the ADH structural genes of the two species. There are about 30 substitutions within 200 base pairs upstream from the putative distal (adult) promoter but only one substitution within that distance from the proximal (larval) site. This is true even though the latter sequences lie within an intron with respect to the adult transcript. The latter level of sequence conservation is comparable to that seen in $\mathrm{ADH}$ coding sequences while the former is close to that seen in the two introns within the coding region. It is tempting to speculate that sequence conservation near the putative larval promoter is related to the conservation of ADH regulation in larvae, but a firm conclusion awaits further work.

Explanations at other levels are also possible. Since both the processing of transcript into messenger and the sequence of the untranslated leader on the completed messenger differ in larvae and adults, signals affecting processing efficiency, translational efficiency and messenger stability all might evolve independently with respect to the two stages. We cannot exclude even structural differences with some indirect effect on realised developmental pattern. However, simple differences in catalytic properties seem to be excluded by the immunological data. One might obtain the observed patterns by altering relative stability of the enzyme in a tissue and stage specific way (Beutler, 1983), but the constraints on such a model are severe. Note, for example, that the larval isozyme ratio, established during a period of rapid net ADH synthesis, is maintained throughout pupal life, during which total activity is declining. Then, the shift to the adult ratio takes place during another period of rapid net synthesis. This is most easily understood in terms of a shift in relative rates of synthesis. Despite uncertainties concerning the mechanisms involved, this case provides evidence in favour of the central point of our previous model (Dickinson, 1983), which is that complexity or multiplicity of cis-acting regulatory components could account for the observation that various aspects of the developmental programme of a specific gene can change independently during evolution. More detailed molecular analysis of the present case should be very interesting. 
Acknowledgements. We thank W. Sofer for supplying antibody and M. Ashburner for sharing unpublished data. Ann Gallenson and Paula Fey provided technical assistance with some aspects of this work. Supported by NIH Grant HD 10723. MDB is a postdoctoral NRSA trainee supported by NIH grant 5-T32-GM07825.

\section{REFERENCES}

ALLENDORF, F. W., KNUDSEN, K. L. AND LEARY, R. F. 1983. Adaptive significance of differences in the tissue-specific expression of a phosphoglucomutase gene in rainbow trout. Proc. Nat. Acad. Sci., USA, 80, 1397-1400.

AYALA, F. J. AND MCDONALD, J. F., 1980. Continuous variations: Possible role of regulatory genes. Genetica 52/53, 1-15.

BENYAJATI, C., PLACE, A. R., POWERS, D. A. AND SOFER, W. 1981. Alcohol dehydrogenase gene of Drosophila melanogaster. Relationship of intervening sequences to functional domains in the protein. Proc. Natl. Acad. Sci., USA 78, 2717-2721.

BENYAJATI, C., SPOEREL, N., HAYMERIE, H. AND ASHBURNER, M. 1983. The messenger RNA for alcohol dehydrogenase in Drosophila melanogaster differs in its $5^{\prime}$ end in different developmental stages. Cell, 33, 125-133.

BENYAJATI, C., WANG, N., REDDY, A., WEINBERG, E. AND SOFER, W. 1980. Alcohol dehydrogenase in Drosophila: Isolation and characterization of messenger RNA and cDNA clone. Nucleic Acids Res., 8, 5649-5667.

BERK, A. J. AND SHARP, P. A. 1977. Sizing and mapping of early adenovirus mRNAs by gel electrophoresis of S1 endonuclease-digested hybrids. Cell, 12, 721-732.

BEUTLER, E. 1983. Selectivity of proteases as a basis for tissue distribution of enzymes in hereditary deficiencies. Proc. Nat. Acad. Sci., USA, 80, 3767-3768.

CLARKE, B. 1975. The contribution of ecological genetics to evolutionary theory: Detecting the direct effects of natural selection on particular polymorphic loci. Genetics (Suppl.), $79,101-113$.

CLARKE, B., CAMFIELD, R., GALVIN, A. AND PITTS, C. 1979. Environmental factors affecting the quantity of alcohol dehydrogenase in Drosophila melanogaster. Nature, 280, 517-518.

DAVID, J. 1977. Signification d'un polymorphisme enzymatique: La deshydrogenase alcoholique chez Drosophila melanogaster. Ann. Biol., 16, 451-472.

DA VID, J. R. AND BOCQUET, C. 1977. Genetic tolerance to ethanol in Drosophila melanogaster: Increase by selection and analysis of correlated responses. Genetica, 47, 43-48.

DAVID, J. R., BOCQUET, C., ARENS, M. F. AND FOUILLET, P. 1976. Biological role of alcohol dehydrogenase in the tolerance of Drosophila melanogaster to aliphatic alcohols: Utilization of an ADH-null mutant. Biochem. Genet., 14, 989-997.

DAVID, J., FOUILLET, P. AND ARENS, M. F. 1974. Comparison de la sensibilite a l'alcool ethylique de six especes de Drosophila du sous-groupe melanogaster. Arch. Zool. Exp. Gen., 115, 401-410.

DICKINSON, W. J. 1980a. Evolution of patterns of gene expression in Hawaiian picture winged Drosophila. J. Mol. Evol., 16, 73-94.

DICKINSON, w. J. 1980b. Complex cis-acting regulatory genes demonstrated in Drosophila hybrids. Dev. Genet., 1, 229-240.

DICKINSON, W. J. 1983. Tissue-specific allelic isozyme patterns and cis-acting developmental regulators. In Rattazzi, M. C., Scandalios, J. G. and Whitt, G. S. (eds.) Isozymes, vol. 9. Alan R. Liss, Inc., New York.

DICKINSON, W. J. AND CARSON, H. L. 1979. Regulation of the tissue specificity of an enzyme by a cis-acting genetic element: Evidence from inter-specific Drosophila hybrids. Proc. Natl. Acad. Sci., USA, 76, 4559-4562.

DOBSON, D. E., DAYAN, E. AND WILSON, A. C. 1979. Evolutionary derepression of lysozyme. Fed. Proc., 38, 674.

GOLDBERG, D. A. 1980. Isolation and partial characterization of the Drosophila alcohol dehydrogenase gene. Proc. Natl. Acad. Sci., USA, 77, 5794-5798.

HEDRICK, P. W. AND MCDONALD, J. F. 1980. Regulatory gene adaptation: An evolutionary model. Heredity, 45, 83-97.

KING, M. C. AND WILSON, A. C. 1975. Evolution at two levels: Molecular similarities and biological differences between humans and chimpanzees. Science, 188, 107-116.

LAURIE-AHLBERG, C. C., MARONI, G., BEWLEY, G. C., LUCCHESI, J. C. AND WEIR, B. S. 1980. Quantitative genetic variation of enzyme activities in natural populations of Drosophila melanogaster. Proc. Nat. Acad. Sci., USA, 77, 1073-1077. 
LEHRACK, H., FIAMOND, D., WOZNEY, J. M. AND BOEDTKER, H. 1977. RNA molecular weight determination by gel electrophoresis under denaturing conditions: A critical reexamination. Biochemistry, 16, 4743-4751.

MACINTYRE, R. J. 1982. Regulatory genes and adaptation: Past, present, and future. Evolut. Biol., 15, 247-285.

MARKERT, C. L., SHAKLEE, J. B. AND WHITT, G. S. 1975. Evolution of a gene. Science, 189, $102-114$.

MCDONALD, J. F. AND AVISE, J. C. 1976. Evidence for the adaptive significance of enzyme activity levels: Interspecific variation in alpha-GPDH and ADH in Drosophila. Biochem. Genet., 14, 347-355.

MCDONALD, J. F. AND AYALA, F. J. 1978. Gene regulation in adaptive evolution. Canad. J. Genet. Cytol., 20, 159-175.

MCDONALD, J. F., CHAMBERS, G. K., DAVID, J. AND AYALA, J. F. 1977. Adaptive response due to changes in gene regulation: A study with Drosophila. Proc. Natl. Acad. Sci., USA, $74,4562-4566$.

MCKENZIE, J. A. AND PARSONS, P. A. 1972. Alcohol tolerance: An ecological parameter in the relative success of Drosophila melanogaster and Drosophila simulans. Oecologia, 10, 373-388.

O'DONNELL, J., MANDEL, H., KRAUSE, M. AND SOFER, W. 1977. Genetic and cytogenetic analysis of the ADH region in Drosophila melanogaster. Genetics, 86, 553-566.

RABINOW, L. AND DICKINSON, W. J. 1981. A cis-acting regulator of enzyme tissue specificity in Drosophila is expressed at the RNA level. Mol. Gen. Genet., 183, 264-269.

THATCHER, D. R. 1980. The complete amino acid sequence of three alcohol dehydrogenase alleloenzymes $\left(A d h^{\mathrm{N}-11}, A d h^{\mathrm{s}}\right.$ and $A d h^{\mathrm{UF}}$ ) from the fruitfly Drosophila melanogaster. Biochem. J., 187, 875-886.

THOMAS, P. S. 1980. Hybridization of denatured RNA and small DNA fragments transferred to nitrocellulose. Proc. Natl. Acad. Sci., USA 77, 5201-5205.

VAlentine, J. W. AND CAMPBEll, C. A. 1975. Genetic regulation and the fossil record. Am. Sci., 63, 673-680.

VAN DELDEN, W. 1982. The alcohol dehydrogenase polymorphism in Drosophila melanogaster: Selection at an enzyme locus. Evolut. Biol., 15, 187-222.

WHITE, R. T., DOBSON, D. E., WILSON, A. C., JOLLES, J., SCHOENTGEN, F. AND JOLLES, P. 1983. Ruminant stomach lysozymes: Functional peculiarities, amino acid sequence and genomic cloning. Fed. Proc., 42, 1971.

WHITT, G. S. 1981. Evolution of isozyme loci and their differential regulation. In Scudder, G. G. E. and Reveal, J. L. (eds.) Evolution Today. Proc. 2nd Int. Cong. Syst. Evol. Biol., pp. 271-289.

WILSON, A. C. 1976. Gene regulation in evolution. In Ayala, F. J. (ed.) Molecular Evolution. Sinaurer Press, Sunderland, Mass., pp. 225-234.

WILSON, A. C., CARLSON, S. S. AND WHITE, T. J. 1977. Biochemical evolution. Ann. Rev. Biochem., 46, 573-649.

WOODRUFF, R. C. AND ASHBURNER, M. 1979a. The genetics of a small autosomal region of Drosophila melanogaster containing the structural gene for alcohol dehydrogenase. I. Characterization of deficiencies and mapping of $A d h$ and visible mutations. Genetics, 92, $117-132$.

WOODRUFF, R. C. AND ASHBURNER, M. $1979 \mathrm{~b}$. The genetics of a small autosomal region of Drosophila melanogaster containing the structural gene for alcohol dehydrogenase. II. Lethal mutations in the region. Genetics, 92, 133-149. 